\title{
Avicenna's ideas and arguments about mind and brain interaction
}

\author{
Mohammad Jamali ${ }^{1, a, b}$, Mehdi Golshania ${ }^{a, b}$, Yousef Jamalic \\ ${ }^{a}$ Department of Physics, Sharif University of Technology, Tehran, Iran \\ ${ }^{b}$ School of Physics, Institute for Research in Fundamental Sciences (IPM), Tehran, Iran \\ 'Department of Applied Mathematics, School of Mathematical Sciences, Tarbiat Modares University, Tehran, Iran
}

\begin{abstract}
Mind and brain/matter interaction is one of the important and controversial issues in Islamic philosophy. In fact, in the resources of Islamic philosophy, one of the basic parts of philosophical discussions is related to mind's nature and its interaction with the brain. Especially, in Avicenna's philosophy, there are many articles and books which have addressed the topic of mind and brain and the relation between them. Avicenna was a profound philosopher, an expert physicist and a proficient physician of his time. Because of his experimental proficiency in medicine and surgery and his deep philosophical analysis, his discussion about mind and brain is very interesting for our time, due to recent advances in neuroscience. In this article, we have explained one of Avicenna's arguments (in his famous opus "al-Isharat") about the incorporeity of mind (self), which is very close to modern neuroscience and physics literature. In addition, we explain his model of mind and brain interaction. Avicenna described the mechanism of the causal effect of mind on the brain via a third identity, which works as an interface between them (in his main book "al-Shifa"). We try to illustrate his model by the use of some examples, inspired from modern physics. Also, we explore the philosophical constraints which must be considered in any model of mindmatter interaction, within the Islamic philosophy framework. In fact, we propose a new understanding of Avicenna's philosophy which is in agreement with modern physics and neuroscience.
\end{abstract}

Keywords: mind brain interaction, Avicenna, consciousness, cognition, incorporeity of mind, mind matter interaction

\section{Introduction:}

Islamic philosophy is a realistic philosophy, based on principles similar to those of Aristotle's philosophy. The two mainstreams of Islamic philosophy are Avicenna's (Avicenian) philosophy and Sadra's (Sadrian) philosophy. Avicenna was a profound philosopher and a pioneer in physics and biology (medicine). Besides his famous book on medicine, called "Canon", an important part of his philosophical books (especially "alShifa" and "al-Isharat") are about natural laws and physics. Furthermore, although in his framework mind and soul ${ }^{2}$ are issues related to theology and metaphysics, but because of the relation between mind and

\footnotetext{
${ }^{1}$ Corresponding author Email address: byasinjamali@ipm.ir

2 'Soul', 'self' and 'mind' are three different concepts in Islamic philosophy. The phrase of 'soul' refers to the material subtle body (vaporous soul) which is spread all over the body via the nerves. And the 'self' refers to the spiritual nature of humankind, it is the incorporeal essence of humankind, which titled 'human self'. The 'self' is the origin of life for material substance (body), which is the cause of the creation of special treatment for matter and manage (govern) body activity. Therefore, in Avicenna's philosophy, the other kinds of 'self' are defined such as 'animal self' or 'vegetable self'. The 'mind' refers to some incorporeal ability of 'self' such as thought and thinking. In recent literature and in 'Kalam' the soul and self can be considered the same as the spiritual nature. At
} 
body (Matter), in which mind controls and affects body, this subject is discussed in the natural science part of his books (Malekshahi, 1990a).

The mind-brain interaction introduced in many of his books, especially in the physics part of al-Isharat, in the physics part of al-Shifa, which is called psychology of Shifa (Latinus, Van Riet, \& Verbeke, 1973; Rahman, 1959), and in the Treatise of Self in Persian. In addition, in his mystic opus: "Hayy ibn Yaqzan", he addressed the mind-body properties, in a mysterious and mystical language (Corbin, 2014).

In Avicenna's perspective, an object needs to have a soul aspect, if its behavior has one of the flowing properties: behavior via free will or an abnormal dynamics, with no physically known forces at the world (Avicenna(Ibn-Sina), 980-1037d). Therefore, there are two kinds of soul: the astral soul and the earthly soul (vegetable, animal and human soul). Due to the fact that, in this view, the dynamic of the sky is not natural and cannot be explained by the known physical forces, it must have an ego aspect, even though it has no free will and its dynamics is predictable. In fact, in ancient physics there are no especial forces that would cause the turning of stars (Avicenna(Ibn-Sina), 980-1037e). The human or animal soul stabilizes the living body which is composed of opposite temperaments, and also controls it (Avicenna(Ibn-Sina), 9801037b). In modern language, we can say that it helps to stabilize the very low entropy of biological organisms and has causal effects on the brain dynamics.

Avicenna has a good proficiency in medicine and anatomy. His documents about the human brain anatomy confirm this fact. He discusses about different areas of nervous system and brain. For example, he addresses vision's nervous system and says: the path of its nerves start from behind the eyes and reach together in the middle of the brain (cross-shape) and are detached again (Avicenna \& Danaseresht, 1985; Avicenna \& Madkour, 1969; Rahman, 1959). Nowadays, it is well known that visual information coming from the eye goes through the optic chiasm and then reaches the lateral geniculate nucleus in the thalamus). Avicenna explains that the visual awareness and consciousness don't occur behind of eyes or in the optic chiasm, but it occurs after than the cross-shape (optic chiasm) specially in the common sense (bentasia) which is in the forebrain (Avicenna \& Ibrahim Madkour, 1970b). He argued that according to empirical data when this area of brain is damaged, the vision is lost (Avicenna \& Danaseresht, 1985; Avicenna \& Madkour, 1969)(see appendix.A). In the Psychology section of al-Shifa, Avicenna after a preliminary description of mind and its definition, discribes different brain areas and external nervous system. Then, after explaining the brain function and its anatomy, he assigns many forces of soul to the brain function such as force of imagination and illusion, memory power and its location, force of visual and auditory system. He argues philosophically that some of mind's properties and functions cannot be explained via matter and brain areas. In fact, there are some properties in mind's function which are not compatible with material properties. These issues are considered to be due to the incorporeity of mind (soul). The famous floating man argument is explained in different references (Black, 2008; Kaukua, 2015; Marmura, 1986; Toivanen, 2015). In this article we first explain an interesting and deep argument which was proposed by Avicenna (in the "Physics part of al-Isharat" in the continuation of the floating man argument), about of the incorporeity of mind and its irreducibility to matter.

To solve the problem of interaction between mind, as an immaterial object, and brain, as a material object, he proposed a model for the interaction mechanism. He explained how a subjective phenomenon can

this article when we use the 'soul', 'self' or mind, they refer to the incorporeity essence of the human, Unless another concept is emphasized. 
affect the brain dynamics, and conversely, how the brain function can affect the mind and subjective experiences. Despite the presence of other models of mind-brain interaction, he first discusses the mechanism of how mind affects the brain, and then he explains how under this mechanism the brain function can affect the mind. We see that to solve both aspects of mind-brain interaction are very difficult. For example, in the modern quantum models of consciousness, only one of these aspects is explained (Beck \& Eccles, 1994; Hameroff \& Penrose, 2014; Stapp, 2004). We try to illustrate these mechanisms under our modern physics understanding, and finally indicate some philosophical constraints on the mindbrain interaction mechanism under Avicenna's philosophy. In this article, we tried to present (rephrase) Avicenna's argument and his model through modern scientific terms and language in order to be more understandable for those who are not familiar with the language of old philosophy. In addition, we took Avicenna's model of perception of general concepts and extend it to every perception.

\section{Avicenna argument of incorporeity of mind}

\subsection{Incorporeity of mind}

The term "incorporeity" means being free of matter properties (i.e. being immaterial). The term "matter" refers to a substance ${ }^{3}$ which can potentially accept different states and actualities (Avicenna \& Ibrahim Madkour, 1970d). "Physical substance" is a substance that has three extensions in space (Avicenna \& Ibrahim Madkour, 1970d; Malekshahi, 1990b). In term of physics it means that an object has volume, and in terms of mathematics it means that there is at least one neighborhood to a point in three dimensional space at which an object exists and occupies a volume. When an object is considered to be immaterial, it means that it has no material properties and its essence has no dependency on matter. For example, it does not have a location and cannot be sensible. Therefore, we can consider the incorporeity of mind as

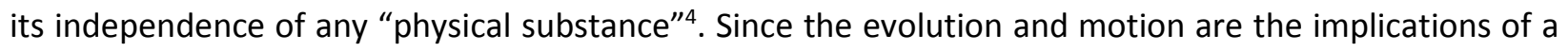
physical substance, which is composed of matter (potentia) and form (actuality), thus we can define a physical substance as a substance which has four extensions in space-time or has space-time properties. This understanding is compatible with both the theory of relativity and Sadra's philosophy about motion (evolutionary description in Sadra's philosophy).

Nevertheless, to be an immaterial or nonphysical substance does not mean that it is outside of physics. In modern physics, there are some concepts which are immaterial, on the basis of this definition. For example, the concepts of information and entropy are immaterial, because they are not spatial quantities. Similarly, some emergent properties in physics do not have space-time characteristics.

Because our sensory organs are material, and are developed to detect and sense the material part of our environment, the visible level of our surrounding world is only its material level. But, we can discover and realize the immaterial level of our world via its effects on the material level. In fact, we don't develop our

\footnotetext{
${ }^{3}$ In Islamic philosophy, substance used to mean essence, nature and basis, which is in opposite to "accident", which does not need any location for being and creation (Aminian, 2018). A simple explanation is that some phenomena need another entity for creation and survival. For example, the perimeter of a surface is a quantity which exists if there is a surface and it cannot exist without a surface.

${ }^{4} \mathrm{~A}$ matter in its existence has an actuality, which is called the "form" of matter. In other words, a corporeal (physical) substance is composed of matter and form. Considering the incorporeity of mind as a non-physical substance is denial of considering it as a form for body. Aristotle considers the self as the form of a body, but this has no supporter among Islamic philosophers (Moallemi, 2016). Avicenna considers the 'self' (human or animal self) as a different substance than the 'form'.
} 
theoretical models in physics only via our observations. In fact, many of our assumptions and hypotheses are not empirical and are not obtained only by sensory tools. They are the results of our imagination and thinking. Therefore, the incorporeity of mind and its non-physicality means its non-sensibility, nonempiricality and immateriality. Usually the term "physics", in the context of "nonphysical" word, refers to classical physics and classical properties. These properties are reducible to material and atomistic parts, space-time dependency, and microscopic Individuality. For example, when Penrose says that consciousness is nonphysical, he means that its function is non-computational, as in QM the reduction of wave function is not computational and predictable )Hameroff \& Penrose, 2014; Penrose, 1994).

Mind in the view of most of the Islamic philosophers has two main properties: one is its space-time independency and the other is its independency of matter, especially in its survival or in some parts of its functionality. The incorporeity of mind is its abstraction of the physical substance. In fact, mind is not a material substance, and it has no existential dependency on matter. In the Avicenna's perspective it is not inherent on (of) matter as "form" is. In the following, we explain our understanding of one of the Avicenna's arguments for the incorporeity of mind, as is explained in the physics part of al-Isharat (Avicenna(Ibn-Sina), 980-1037a) \& appendix.A.

\subsection{Demonstration}

Self-awareness means a conscious awareness of one's own character and feelings. In any case and state, a person has a perception of himself (even in sleep, drunkenness, sadness, happiness, etc.) and finds himself without needing to think about something or doing a special work. A person perceives himself at the present, at least, even though he may not remember the past. There are two concepts in any perception: the percipient (apprehender) which perceives and the perceived thing (perceptible). In the case of self-awareness too, one may consider these two concepts. Now, the first question is whether there is an intermediary between the percipient which is " $\mathrm{l}$ " and the perceived which is " $\mathrm{I}$ " too? Do we perceive ourselves by the use any intermediary? One may assume that it is through an intermediary that one perceives himself, for example by a physical action or by thinking about them and their feedback. This is like the case that we find ourselves by seeing our image in the mirror. If a person who has no perception of himself, looks at an action of his mind, at best, he will argue that a person or a mind (which is not necessarily herself) has done this action. But, the necessity of understanding the relation between an action and self, is the perception of the self before it, and this understanding needs prior self-awareness. Otherwise, how can we relate it to ourselves when we don't have any perception of ourselves? Therefore, the assumption of the existence of an intermediary for self-awareness is false, and the mind, whether it is material or immaterial, immediately perceives itself. It's possible that an animal or an infant, who is placed in the front of a mirror, plays with its image, without knowing that it is its own image.

After this lemma, we focus on the nature of percipient and perceived. what are percipient and perceived? Obviously, our perception is not our skin or blood or meat or bone, because by damaging or replacing them, our perception of ourselves doesn't change. There are three possibilities: A. our perceived is the brain or part of its neural networks, its chemical molecules, etc. $B$. it is the dynamics or pattern of electrical neural network's activity, or the transformation of electrical pulses and electromagnetic fields due to electrical ionic currents. $C$. it is an emergent essence at a higher level, with new and different laws ${ }^{5}$. The

\footnotetext{
${ }^{5}$ It is necessary to discuss briefly the different levels which exist in modern physics. We explain it by the use of examples. Many fields of physics have some levels of concepts and laws which cannot be explained on the basis of
} 
first two cases are rejected, because each person recognizes what he understands of himself, and his selfawareness is other than these qualities. We understand these concepts and quantities via physics or by autopsy, and before these, a human perceives himself. As Libet mentioned in (Libet, 1979; Libet, 2009a), by knowing all of the neural patterns of the brain activity, it is impossible to obtain the related mental state unless one asks a subject about his/her mental states and has a subjective report. I.e. without any previous knowledge and experiment. For example, suppose that for the first time one observes a new pattern. By this pattern per se there is no way to understand the related mental state. Therefore, mental states cannot be equal to or the same as neural patterns. One may say that the perceived is the effects and influences of these brain activities. The question is whether the percipient, which is " $I$ ", is equal to these patterns? In this case, it is assumed that the neural network perceives itself via the effect or influence of mind, but we showed the falsehood of this claim.

The third case is when the perceived is an emergent essence which is novel and irreducible to the brain. This could be divided to two types: one is that this novel substance is only influenced by the brain and neural level ${ }^{6}$; the other is that it is the origin of the effects on the brain. If we accept the first situation, awareness and consciousness cannot be attributed to it, because we showed that the perceived and percipient are the same. Therefore, this emergent entity must perceive itself, and this is a new and novel action, more than the lower level. Also the self-awareness itself can cause some effects on the brain. We avoid pain or danger, because we attribute it to ourselves and this attribution needs the priority of selfawareness. Therefore, if the mind is an emergent entity, it must be affective, and not only affected.

We showed that mind, which is responsible for self-awareness and consciousness, can only be an emergent and novel essence which can be the origin of causal influences. It is worth to note that, by this argument there is no way to obtain facts about the nature of mind or mechanism of its influence on itself and on the brain's activity.

Due to the fact that different persons and different brains have different personalities and selves, it is closer to truth that the brain must be effective on the creation of this novel emergent level, and because of the independency of self-awareness on the kinds of neuron cells or the moment to moment change of neural activity pattern and their connections, it is closer to truth that mind has independency from the

concepts and laws at the fundamental particle's level and is not necessarily reducible to it. This is especially true for the fields of condensed matter, cosmology and biology. At the fundamental particle's level, there are special laws and concepts such as electrical charge, spin and etc. As soon as some of these particles interact with each other, it is observed that some novel concepts and laws emerge which do not exist at the previous level and is related to the many body level. The effects of the whole system, in some cases, are not explainable by its components. As George Ellis has discussed in detail in his book "Top-Down Causation", some of these levels have causal effects on the lower levels. For example, in biology, the level which is related to the whole brain activity affects the behavior and function of neurons, and the neurons' level affects the intra cellular activity such as protein production and intra dynamics of neuron, and this continues to the atomic level. )Ellis, 2016)

${ }^{6}$ In the Sperry's primary model of the mind-brain interaction it is considered that the mind and mental states are the emergent properties and are in one to one correspondence with the brain activity patterns. These mental states are completely dependent on the brain patterns and are also effective on them, but they do not have additional effects independent of the brain. Some decades later, due to the issues of free will and volition, he accepted that the mental states have some causal effects that can have independent control on the brain activity. )Doty, 1998; Sperry, 1976) 
brain's matter ${ }^{7}$. In fact, this emergent level can be due to the level of brain's matter but has causal independence.

The neural level can be considered as preparative cause for this emergent quantity or as its efficient cause. If it is the efficient cause for mind, how can an effect and an existence, which has everything from its cause, have an effect on its cause? While we show that mind is the origin of some influences on the neural activity. Therefore the brain can only considered as a preparatory causation level for the creation of mind or for creating a relationship between the mind and the brain ${ }^{8}$. Also, it is rational and likely for this emergent level to survive after the damaging of the brain, as it exists with the change and evolution of the brain matter and with the losing of prior neural patterns and the creation of novel patterns.

The human mind has unique features that cannot be explained at the level of material or physical matter. The main features are unity and integrity, non-locality, non-temporality, and the influencing of the underlying levels, and irreducibility to the neuronal or microscopic levels. Although these features are present in modern physics, but they are not explained by a materialistic (positivism) attitude and is not consistent with the classical physics.

In summary, we have argued that the self or mind is an essence independent of neural and brain level, being affected by it and having effect on it. As argued, the mind is not the same and equal to the material level of the brain. Similarly, it is not the same as any of physical concepts such as electromagnetic field, energy field, gravitational field, wave function, quantum field, etc. This is because our perception of ourselves and our self-awareness are far from the picture that physics presents for these quantities. On the other hand, it cannot be said that we don't perceive ourselves but merely by observing our actions and effects we understand our self. We showed that we have a perception of "our" in the words "our action" before understanding our action. I.e. self-awareness must be occurring instantaneously and immediately.

\section{How mind controls and affects the brain?}

\subsection{How two different entities can affect each other?}

We experiment and observe two aspects of ourselves; the physical and the mental aspects. At the first glance, we observe a reciprocal relation between mind and brain. On the one hand, mental state is affected by the brain activity. In fact, via our physical and neural tools (such as visual system, auditory system, sensory receiver and etc.) we can be informed and can get a perception of our brain, body and the surrounding world. It is obvious that some manipulation (chemically or electrically) on the neural activity, or in some special areas of a brain, can affect and change the mental states. On the other hand, our mental states affect the brain activity. These effects occur both in the non-perceptional related areas of the brain and in the awareness related areas (Libet, 2009c).

\footnotetext{
${ }^{7}$ As Libet mentioned, due to the neuroscience and cognitive science researches, there are many of brain areas for which the stimulation does not affect the mental states directly and does not have a perceptional effect. There is no reason that we say any of the mental states have a corresponding pattern and neural activity in the brain:

"Also, it is possible that some mental phenomena have no direct neuronal basis (see Chapter 3 ) and it is also possible that the conscious will does not always obey the natural laws of the physical world (see Chapter 4)." (Libet, 2009b)

${ }^{8}$ Avicenna propounds that when the body reaches an enough perfection and moderation, the incorporeal mind is emanated to it. Mulla Sadra discussed that when the matter gets enough perfection and obtains necessary complexity, a novel dimension, which is the incorporeal self, is created in its evolutional motion (current).
} 
About the mind-brain relation, there are two philosophical and physical challenges. One is an ontological issue concerning the possibility of interaction between mind, as an immaterial substance, and brain, as a physical substance. The other is the quality of this interaction; i.e. the mechanism of this relation and effectiveness.

The main argument for the possibility of a phenomena is its occurrence. The mind and brain are interconnected, and this is natural, but how are they connected to each other? Philosophy, physics and biology must explain this, now or in the future. Some models of quantum consciousness claim that they can explain some parts of this relation.

There are no philosophical arguments for the impossibility of the modality of mind-brain relation. As we mentioned in the previous part, the incorporeity of mind doesn't mean that it is an unnatural thing. It only means that its properties could not be explained by classical physics. Although mind has no physical or material substance, it has its own substance and it exists. In addition, different substances have some common properties because all of them are substance. In physics there are some examples of two distinct objects which have an effect on each other. In the general relativity theory, the geometry and the structure of space-time are conceptually different from energy and matter. Yet, through Einstein's equations they have effects on each other. The space-time geometry determines the dynamics of matter and the energy distribution (energy-momentum tensor) affects the structure of space-time geometry. Another example is in the Bohmian quantum mechanics, where the informational wave function (which is not energy or a materialistic quality) affects the particle trajectory and guides it. In addition, there are many physical cases in which a phenomenon or quantity, at a specific level and with the distinct laws, can affect a lower or higher level which has a different description. There are many examples of these types of interaction in cosmology, biology and condense matter physics, which are explained in the Ellis's book "How Can Physics Underlie the Mind?" (Ellis, 2016). Mind has some properties which are not compatible with classical physics. Its main features are nonlocality in space-time, its wholeness and integrity, its irreducibility to components, its intrinsic independency of matter and its non-subordination to matter, its effectiveness on brain, its free will, its power of reasoning and generalization, its ability for abstraction, its consciousness, its self-awareness and its survival without matter. Part of these features are not unfamiliar to physicist. For example, in modern physics, we understand the nature as a nonlocal, nondeterministic, and irreducible to its components, especially in quantum mechanics. In free interaction experiments, it is experimentally confirmed that parts of a system can be informed of other parts without any interaction between them )Elitzur \& Vaidman, 1993; Vaidman, 2001). Some quantities such as energy can be conserved, independent of the physical system and its details. In Bohmian quantum mechanics the pilot wave can survive even after particle detection. These physical concepts and phenomena show that the impossibility of mind-brain interaction, due to the incompatibility of mind's properties with classical physics and the absence of a specific mechanism, is not right.

In Islamic philosophy there is no disagreement about the possibility of interaction between two distinct substances (Lagerlund, 2007). The formal substance can affect the material substance both in the Islamic philosophy and in the Aristotle philosophy, in spite of being difference substances. The important issue in the Avicenian or Sadrian philosophy was the modality and mechanism of this interaction. Sadra tries to solve this issue by creating a continuous connection between mental and material aspects of a phenomenon or object in his gradational explanation of existence. He claims that in the substantial evolution when matter gains enough complexity the immaterial and mental aspects are created, and there 
is a continuous extension from matter to mind. They are not two aspects of one object but they are two parts or two levels of one thing which cannot be used to determine a boundary between them (see (Fayyazi \& Yusufi, 2014)). In Avicenna's philosophical model there is an interface substance between mind and brain. This third substance which transforms the mind effect to the brain or material substance is just the form of the physical substance ${ }^{9}$.

\subsection{Avicenna's model of mind effect on the brain}

In Aristotle's philosophy, in the real world, a physical substance is composed of a unified composition of two substances: matter and form. The form determines how matter is realized, and the matter can potentially have different forms (actualities). Contrary to Aristotle, Avicenna could not accept the identity of formal substance and mental substance ${ }^{10}$. This is because the formal substance can exist only via physical substance and by composition to a material substance, in the real world. Hence, there is no independent action and effect on matter, which is dependent on mind.

However, the form of a physical substance is entangled with its matter and can affect its actuality. On the other hand, its property is very close to that of the mental property: its non-reducibility to parts, its integrity, its informational aspects, etc. Avicenna, in al-Shifa, considered that it is due to the proximity of the substance and the quality of mind to the form, which forms of origins and basics that the formal substance produces of them (Avicenna \& Ibrahim Madkour, 1970c) (see appendix.C). Therefore, mind via the change of form can affect the brain matter. In fact, when a mind imagines a possibility, the formal substance follows the mind, and then if the matter has adequate level of complexity and aptitude, it will accept this form. The prerequisites for the effectiveness of mind on matter, is first at all the existence of tendency and similarity between this mental substance and the specific body/brain. Secondly it is the ability and predisposition of matter for accepting this form. The effectiveness level of mind refers to its power and ability. In summary, when the brain matter has enough complexity and enough aptitude, its related mind can affect it by the change of its form. There are many interesting examples in al-Shifa, e.g. a physician by using some medical tools and the imagination of healthy person can heal a patient. Even a patient by the imagination of a healthy person can heal himself (Avicenna \& Ibrahim Madkour, 1970c).

\subsection{The mechanism of perception, a mind being affected by its related brain}

In Avicenna's view, when a matter reaches an enough sophistication and completeness and a certain level of physical balance, it will gain the ability of pursuing a mind. Then, an effusion takes place, and a soul is breathed into this body, which intrinsically belongs to it. Furthermore, after death, this specific soul, which was breathed into this body, continues to survive (Moallemi, 2016). The soul manages the body through some tools, some of which are material and some are immaterial. In fact, the material agents of soul are the facilities through which mind, via domination over them, controls and guides the body. These material agents of the body, get enough complexity, so that mind can affect them. By exercise, one can develop his/her body's complexity and as a result strengthen body's connectivity to the mind. These levels or regions are not necessarily special areas of a brain, but these can be a novel and subtle level at which the

\footnotetext{
${ }^{9}$ In Avicenna philosophy the first matter which is affected via its form by the soul, is vaporous sprit. The vaporous sprit is a material substance which is very intangible (subtle). As a physical substance, this vaporous sprit is composed of two components: the form and the matter. Avicenna emphasizes that the soul can affect a matter through the form of it.

${ }^{10}$ This soul contains both the human and animal soul (Razi, 1990).
} 
mind can potentially affect it. In modern language It can be an emergent level caused by neural networks' interaction or an emergent quantum wave caused by neurons' quantum connections. It is obvious that due to the substance of mind, it has a proximity to some material forces and is unfamiliar with some others. As a physician, by the use of some tools, can transfer the effect of his mind's imagination of a healthy person to a patient, mind can affect directly some high levels of a brain, and through some tools affect other levels. For example, for running it is not needed to affect directly the muscles, but by affecting some special level of brain, through the nervous system, it can affect the muscles.

Some scholars believe that by considering some material forces for the soul, such as memory, imagination power, common sense force, sensory system, visual force, auditory force, etc., Ibn Sina considered the perception to be material too. In our view, this is not true, because matter in Avicenna's framework cannot have any perception and understanding, even a partial perception. The perception is only under the realm of the incorporeal mind (see appendix. A). Therefore, when he named these material parts (brain) "the force and strength of soul", his aim was that mind for getting information and perception, gets help from these agents. Avicenna frequently mentioned in al-Shifa and al-Isharat that these agents sometimes fail to obey the command of the soul (Avicenna \& Ibrahim Madkour, 1970a). Therefore, the perception refers to mind, which is independent of matter.

Avicenna, after a comprehensive description of the brain components, their functions and their locations in the skull, and their relation and interaction, tries to explain the mechanism of perception, especially the perception of general concepts. The soul after recruiting these forces, by exploring what emerged from these forces, reaches to enough perfection and capacity (due to the relationship between mind and formal substance) where, by connection to higher levels beyond mind (active intellect), a proper form is donated to it. Similar to mind's effect on the brain, a higher level above the mind gives it a proper form for its state, when it gets the adequate ability due to the brain effects. Then, mind finds this form through intuitive knowledge directly. This is a novel perception. In fact, mind doesn't reach to this new understanding via abstraction of what is in the brain, although it was partially separated and abstracted from external world through sensory system. But the effects and influences of these processes in the brain gives the mind substance a capacity to receive a form with properties which are appropriate for what is influenced by the brain. Due to the fact that at higher levels of incorporeity there are no miserliness, proportion to the mind's capacity, a proper form is given to it, Fig.1.

"Therefore, when the faculty of intellect is informed of imagination details (faculty of imagination), and the light of Active intellect, which is in ourselves, is shined on them, it become immaterial and free from the (properties of) matter and their attachments to it (matter), and is printed in our rational soul. It transfers from imagination to intellection neither by itself (by virtue of itself, non-in-itself) nor by that concepts that is impressed on the material attachments _...., inherently incorporeal_creates (new) like itself, but it means that the investigation of it, (i.e. by reflecting of these things in our imagination) prepares the soul to receive a form free from matter from Active intellect...

... Such that is the intellective soul when investigate those imagination forms, and the light of active intellect connects to it (soul), through a type of connection, it disposes to which the light of active intellect creates on it those forms which is incorporeal from the (material) impurities." (Avicenna \& Ibrahim Madkour, 1970c) \& [appendix.B] 
"The soul's multiple managements of the sensible images and the intelligible archetypes, which are in the representational power and in memory [respectively], endow the soul with the preparedness for accepting from the separate substance the abstraction of these images..." (Inati, 2014) \& [appendix.A]

A question may be raised that due to the proximity between the essence of soul and the form, when a special form of matter is formed (through the connection with environment and analysis of the brain forces), the mind perceives it and is affected by it. Notice that what can be inhere on the mind, as an incorporeal substance, which we called it perception, cannot inhere on the material form. Therefore, the mind can only be affected by this material form to earn the capacity of accepting from a higher level ${ }^{11}$.

As Avicenna notes ${ }^{1 r}$ that this effusion is related to the recipient's capacity, and the essence of existence is not emanated. What is engraved in mind must have two features: first, it is a mental state, and secondly, it is proportional to the ability and capability (is) obtained by the mind. The same process is valid in the case of mind's effectiveness on the brain. What is imagined by the mind affects the brain and its form. This effect is proportional to the brain's matter capacity. For example, when one imagines the universal concept of humans, its effect on the imaginative faculty is a particular unit which is not a universal concept. It is a person in human shape. Avicenna by considering this fact, indirectly describes the veridical dream, seeing the illusory premises and unreal objects in awakening, or seeing of imaginal form of incorporeal actual.

Avicenna considers two aspects for the soul: one regulates and stimulates body (brain) and is affected by it, and is called practical intellect. The other one, by connecting to the upper world (active intellect) receives the form and perception which is called conceptual intellect. (Avicenna(Ibn-Sina), 980-1037c)

It is probable that, the reason for correspondence between mental state and brain state is due to mind's effect on the brain. The choice of any special actuality and form, among various possibilities for the brain material, is determined after the perception step and is caused by "intellectual intellect" via "active intellect". This presumption is compatible with the neuroscience empirical data. More clearly, there are two steps or levels: the first is the button-top influence; when the brain, via interaction with the external

\footnotetext{
${ }^{11}$ In fact, the soul changed from ignorance to knowledge, i.e. it moved from potentially to actuality. According to the section "the physics part of philosophy", this motion needs an external cause. Therefore, the soul due to its integration and unity cannot be the cause of abstraction from matter to mind. "the human soul is certainly "potentially intelligent", which then become "actually intelligent". But anything which is actualized from potency needs a cause. Therefore, there is a cause here too, which gets (translate) our soul from potency to actuality. Furthermore, as it is the cause of emanation of intellectual forms, so it is an intellect, which incorporeity, the principles of intellectual forms are actually existing in it (Avicenna \& Ibrahim Madkour, 1970) \& [appendix.B].

12 "Thus, when the rational soul gets a relation with the forms, through the Active intellect it receives something which in some sense is of the same genus and in another sense is different. Therefore, as the pictures received from the sensible things through a light is not the same as those things (, such as when the light shines to the coloreds, it effects on eye that is not the similar to that (light) in any aspects.)

Thus, the imaginations which are potential intelligibilia, become the actual intelligibilia not by itself, but what is captured from them is intelligible, such the effects of the sensible form (on the eye) via the light is not that form itself, but it is another thing, which is appropriate with that (sensible form), that is generated on the head-on recipient through the light. (Avicenna \& Ibrahim Madkour, 1970) \& [appendix.B]
} 
world and internal parts, gains enough amount of capability and as a consequence it gets closer to some of the possibilities. In addition, the soul substance, via interaction with matter, becomes closer to the potentially mental states which are in accordance with the matter possible forms that may be chosen in the future. The second level is top-down effects: the mentioned evolution in the substance of soul, by connection to the active intellect is prepared to receive proper form. This state of mind is named "intellectual intellect". Then, this special form causes the determination of the brain state form and the choosing process occurs. The mind in this situation is termed "practical intellect" (Avicenna(Ibn-Sina), 9801037c). This outlook implicitly shows that even our sensory perceptions are implicitly arbitrary. The reason that it does not look like this, is due to the power of the mind-brain interaction in these processes, and the fact that self is accustomed to this action, which causes it to become a permanent state in mind and brain. This is like running which at first is educational and voluntary, while later it happens unconsciously. It can be seen that when one thinks about an important thing, he does not feel pain completely, or when he is looking for an object, he does not see and hear other images and sounds, etc. Fig.1.
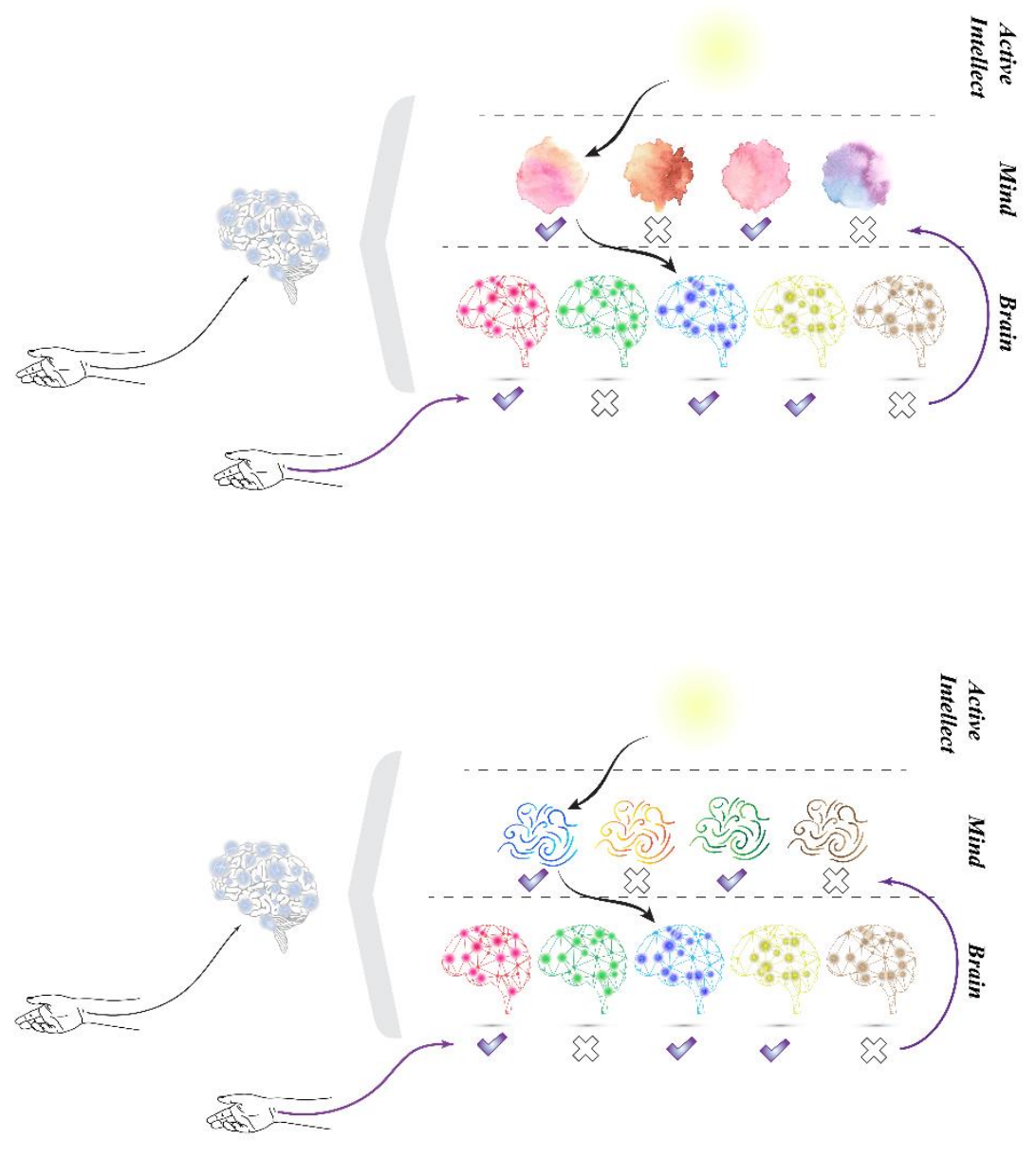

Figure 1. The left hand of above picture is the actual phenomenon which occurs in the physical and observable world. There are the sensory inputs, sensory effects on the brain and brain activity, at the observable level. The right hand is a causal explanation of this phenomenon due to Avicenna's model of mind-brain interaction. In fact, there are two currents of causation. The bottomtop influences are the effects of sensory inputs on the brain's matter to accept potentially some possible patterns as the possible forms. This change and evolution at brain's matter affects the mental substance to reach adequate capacity that can accept some 
possible states from a higher level, called "Active Intellect". These possible states determine in due to the mental dynamic (which can contain volition influences) and bottom-top influences. The downward causation occurs proportion to this ability and capacity in lower levels. In fact, Active Intellect actualizes one of the mental states, among the different possibilities, which potentially exist at in the mind's level. This actualization causes the brain to form one of the possible activities. Finally, one input sensory, one brain activity, and one mental state, is actualized and observed in nature.

\section{Philosophical constraints:}

According to Avicenna and Islamic philosophy, the soul in addition to perception, awareness, free will, and its interaction with the brain, has an important unconsciousness effect on the body. In this view the soul is the cause of stability and durability of the brain and matter. More explanation ${ }^{13}$ is due to the current laws of physics ${ }^{14}$, according to which the material will naturally go to the disintegration and uniformity (maximum entropy). Therefore, to maintain brain's stability, in both quantum and classical perspective, a cause other than the matter itself is needed. Here the mind plays role as an unconscious stabilizing factor.

The mind-brain interaction in the Avicenna's model has a main constraint: the mind cannot affect a special space-time area (point) of the brain. This is because of the incorporeity of mind which was proven before. We showed that the mind cannot be a corporeal substance. Thus, how such a substance can affect a specific time and space? In the following we investigated this subject from three aspects:

a. From the point of view of mind activity: In Avicenna's philosophy, the mind is affected both by higher levels and the brain level. At the higher abstract levels, there are not any corporeal properties. Therefore, the effects which come from a higher abstract level, don't have necessarily the same timing as the material processes. Obviously many of subjective processes occur in a very short time, like an idea which suddenly comes to a mind, or an instant decision or instant willing. But the corresponding material process of the neuronal level needs more time. Benjamin Libet, in his book titled "mind time", describes many experimental data which confirm the difference in the timing of mind processes and the brain processes (Libet, 2009c).

b. From a philosophical view, and considering motion as a unitary whole: At the natural level, the materials are continuously in evolution and change. In the Islamic philosophy. The motion is a unitary space-time phenomenon which has a flowing existence. It is not reducible to some space snapshots. Therefore, the effect of mind on the matter can logically be considered as a starting space-time point of a motion or considered as the effect on all of the motion from the beginning to the end. The first possibility is not acceptable, because, philosophically, there is no beginning

\footnotetext{
${ }^{13}$ According to ancient physics, the living body, due to its composition of materials, has some temperaments, which are opposite to one another, and in normal conditions, in accordance to their natures, get away from each other. When this set reaches a partial balance, it gets the ability of attachment to the soul. More precisely, the soul itself is the cause of this balance in matter, which is naturally unstable. In addition, it is (also) the reason for the survival of the balanced temperaments. But if any external effect disrupts this balance, it leads to the detachment of mind, which is death.

${ }^{14}$ According to the second principle of thermodynamics, any closed thermodynamical system, goes to disorder, uniformity and entropy increase. On the other hands, from quantum mechanical view, i.e. the wave function of matter constantly is in branching and increases the potential possibilities to create numerous states. In other words, the related wave packet, due to natural conditions and constraints, as time goes by will be scattered and obtain all of possible states. The occurrence of one of these possibilities (i.e. the reduction of wave function which is same kind of entropy decreasing), which is very specific and purposeful, that results in a systemic change in the brain patterns, needs an external cause.
} 
point and no quiescence in nature. Physically, there is no quiescence in nature, and even at the zero point (lowest quantum level or even at the absolute zero temperature) there is evolution and dynamics. Also according to physics, if the point of effect of mind on matter can have a significant influence, there is certainly an infinite property like force, and this is out of mind and natural observation. The other possibility is in accordance with our claim that the effect of mind on the matter is not at a special space-time point; rather, it affects the whole motion. It can be considered as a guiding force, or as a creation at the lower level.

More explanation is that the effect of incorporeal mind on the brain must be the same as a creation and existence, because: firstly, the mind is its efficient cause of this effect. Secondly, non creating effects and changes at the material level is due to the causes which are at the same level and it is not necessary to refer it to the causes at higher levels, like the soul. For example, to change a particle's motion and its trajectory, we need a force at the level of the particle or a collision at the same level. But to create a particle or devise or govern a set we need a constraint or a cause at higher levels (there are many examples in thermodynamics and quantum field theory). A creating effect at the material level, in accordance with the nature of matter, is the creation of motion from the beginning to the end.

c. From a mathematical of physical point of view: In physics, the dynamics of physical systems is described by differential equations with the knowledge of initial conditions and the constraints. If we consider the time dependent potentials as a function of particle dynamics being due to the particle or field interactions, whose behavior are both deterministic and continuous, then the generic description of dynamics is determined. If we consider that the dynamical function of a material system (like a particle) is an analytic function ${ }^{15}$, then by knowing the dynamical quantities in the vicinity of a surface at specific time, its past and future are determined. Therefore, if we limit ourselves to analytic functions, the effect on one point is meaningless and the effects itself is an analytic thing or function which continuously has a past and a future, although, they may be ignorable. Therefore, to keep the natural behavior of nature, the effects of mind on the brain must create a space-time influence on the motion and behavior of the system or the particle dynamics.

If we consider the effect of mind at a special point in time, then the function of material dynamics cannot be an analytic function and in the best situation it can be a non-analytic Infinitely differentiable function ${ }^{16}$.

\footnotetext{
${ }^{15} \mathrm{An}$ analytic function is a continuous function which is infinitely differentiable at any point of its domain, for which a Taylor expansion at any point converges to the function itself.

${ }^{16}$ According to the continuity concept in physics, we expect that those functions that describe motion to be infinitely differentiable. Among the functions that can satisfy this condition, but do not have necessarily a memory, are the non-analytic smooth functions. An example of these functions is shown in the following figure which for values smaller than zero is zero and there is no information before the origin (zero point) and after that it is completely smooth and changes continuously. We notice that the effect of a non-temporal thing on the matter can be described by these functions.

$f(x)= \begin{cases}e^{(-1 / x)}, & x \geq 0 \\ 0, & x<0\end{cases}$

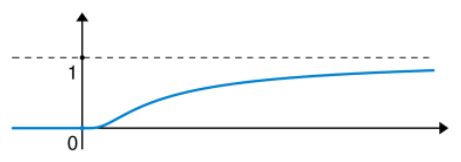


It does not seem that in the brain or in neural level dynamic the classical determinism and physical continuity does not exist. Although in the standard quantum mechanics we don't have determinism at the atomic level, but first of all we have an alternative causal model, such as Bohmian QM. Secondly, if we accept the chance in neural dynamical level, we cannot explain the causal power of mind and the free will, and even the causal sensation and feeling of our will.

\section{Conclusion:}

In this article we reviewed Avicenna's perspective about mind-brain interaction. In his philosophy, the mind is an incorporeal substance which affects the brain through the form of matter. The possibility of this interaction is explained via the fact that soul is created of some principles which are close to the principles of form. We showed that the mental states have some properties that cannot be reducible to physical features. Specially, from self-awareness point of view, one of Avicenna's arguments about the incorporeity of mind was explained via a modern physics approach. It was shown how the mind, as an immaterial substance affects the brain activity through the effects on its form, when the matter reaches an adequate ability and potentiality which corresponds to that form. In Avicenna's philosophy, the soul has two aspects: one refers to the lower level (matter) where this soul state is called the "practical intellect". The other is affected from higher levels which is called the "intellectual intellect". On the other hand, the mechanism of brain's influence on the mind is explained through the down to top preparing influence and top to down actualizing effect. In fact, soul's exploration on the brain causes it to obtain enough capability for being affected by higher levels (action intellect) by connecting to them.

Finally, it was shown that the effect of mind on the brain (i.e. the effect of a non-physical substance on matter) cannot be at a specific space-time point, but it must affect the whole dynamics and the motion of matter from the initial point to the final point (i.e. the space-time extended flowing existence of motion). We think that in Divine's action, the effects, influences and creations are not at a special point, as it leads to the irrelevance of the natural laws, but wisdom implies that its action should not be localized in time and space. Allameh Motahhari, after expressing his wonder of some peoples' act that try to inter the Divine via disorders in nature, says: "If that is the case, it is contrary to wisdom, and in a monotheistic perspective, then should not be any contradiction and discrepancy at any point, but the relationship with higher levels is a kind of existential relation and "cause and effect" relation. The attempt of these people, from the philosophical aspect is to enter the incorporeal causes at the level of lower materialistic horizontal causes, which is not consistent with a philosophical and monotheistic attitude" (Motahhari, 2010).

\section{Appendix. A.}

Translation of some selective parts of al-Isharat, we use the reference (Inati, 2014):

Chapter 2. Admonition: Concerning the Non intermediary Manner in Which the soul is Apprehended "With what do you apprehend 3 yourself at that time, prior to that time, and posterior to it? Also, what is it of yourself that is apprehended? Is that which apprehends [yourself] one of your external senses, is it your intellect, or a faculty other than your senses and what belongs to them? If it is your intellect or a faculty other than your senses by which you apprehend [yourself], then do you apprehend [it] by means of an intermediary or without an intermediary? 
I do not believe that in that case you are in need of an intermediary.6 Thus it is without an intermediary [that you apprehend yourself]. It remains, therefore, that you apprehend yourself without the need for another faculty or an intermediary. 7 Hence it remains that you do so by means of your [external] senses or internal [powers] without an intermediary.8 Reflect further!"

Chapter 3. Admonition: regarding the Nonsensible Nature of the soul

"Do you gather that that which is apprehended of yourself is that [part of] your body that your vision apprehends? No, for if you were stripped of that part of your body, and [if] it were substituted for you, you remain yourself. Or is it what you apprehend by your touch? Again, no, [for] this is nothing other than external members of yourself, whose case is the same as that which was discussed above. Further (p. 347), in the first place, we have supposed that the senses are unaware of their acts. It is evident, therefore, that that which is apprehended of you is not then one of your organs such as the heart or the brain. How [could it be one of these organs] when the existence of such organs is not revealed to you except through dissection? Nor is that which is apprehended of you the whole [of your body] inasmuch as it is a whole. This [must be] clear to you from what you observe by yourself and from what you have been warned about. Therefore, that which is apprehended of you is something other than those things that you may not apprehend when you apprehend yourself and that you do not find necessary for your being yourself. Thus that which is apprehended of you is not one of the things that you apprehend by the senses in any way, nor one of the things that resemble the senses and that we will mention."

Chapter 4. Delusion and Admonition: The soul is Not Asserted by the Mediation of its Acts "Perhaps you will say: "I assert myself only by the mediation of my act." You must then have an act that you assert in the previously mentioned assumption or a movement or something else. For, in our consideration of the previously mentioned assumption, we have isolated you from that. But, with respect to the more general situation, if you assert your act as an absolute one, then from that you must assert an absolute agent and not a specific one - this being yourself in itself. If, on the other hand, you assert your act as an act of yours, you have not thereby asserted yourself by itself. Rather, yourself is a part of the comprehension of your act, inasmuch as it is your act. Therefore yourself is asserted in the comprehension [of your act] before your act. Its being simultaneously [asserted] with it is no less [untrue] than by it. Hence yourself is not asserted by your act."

Chapter 5. Admonition: Regarding Movement and Time as Also Divisible to Infinity

"Thus the fundamental powers that move, apprehend, and retain the temperament are something other than [the temperament]. This you may call the soul. This is the substance that manages the parts of your body and hence your body."

Chapter 6. Regarding the Difference Between That Which Is Continuous in Itself and That Which Has the Capacity for Continuity

"This substance in you is one. Rather, when verified, it is found to be you. This substance has branches of (and) powers that spread in your organs. If by some of your organs, you sense something, imagine, desire, or get angry, then the relation between this substance and these branches imposes a disposition on this substance, such that by repetition it produces some submission or habit and character that take hold of the administrative substance as fixed habits do. Similarly, [this may] happen in a reverse manner. It often begins by the occurrence in [this substance] of a certain intellectual (mental) disposition, then the relation [between this substance and its branches] transports an affection from that disposition to the branches and [from them] to the organs. Reflect on how it is that if you sense the nearness of God, the mighty and illustrious, and think about his omnipotence, your skin shudders and your hair stands at an end.

These reactions and fixed habits may be stronger and they may be weaker. Were it not for such dispositions, the souls of some people would not have been, in accordance with habit, quicker than the souls of some others to become impudent and to flare up with anger." 
Chapter 15. remark: The soul's Preparedness for receiving the intelligibles

"The soul's intense interventions in (multiple managements of) the sensible imaginations (images) and in the spiritual (intelligible) archetypes, which are in the representation (representational power) and in memory [respectively] by use of the faculty of estimation and thought, endow the soul with the preparedness for accepting from the immaterial (separate) substance [Active Intellect] the abstraction of these images and archetypes due to a certain analogy between them [and the soul]. Observation of and reflection on this situation verify that this is so ..."

Chapter 9. remark: Concerning the internal senses

"The first power is that which is called "Common Sense" (al-ḥiss almushtarak) or Phantasia (banțāsiā Its instrument is the spirit that is cast at the basis of the sense nerve, particularly, at the front of the brain."

“... The second power is called representational power (al-mușawwira) or imagination (sensible memory) (al-khayāl). Its instrument is the spirit that is cast in the interior cavity, particularly in the posterior side."

“... The third power is the estimation (al-wahm). Its instrument is the entirety of the brain; but the [part] most proper to it is the middle cavity."

“... this fourth power is called cognition (mufakkira) and if employed by the estimative power it is called imagination (mutakhayyila). Its power is in the first part of the middle cavity."

"The remaining power is memory (al-dhākira). Its power is in the location of the spirit that is in the posterior cavity - this cavity being its instrument."

"What guides people to the judgment that these are instruments is nothing other than the fact that if corruption affects a cavity in particular [the power cast in that cavity] inherits the defect. Further, the consideration of the necessary in the wisdom of the exalted Maker [requires] the advancing of that which takes hold of the corporeal, putting behind that which takes hold of the spiritual and situating in the middle that which manages both of them by judging and reclaiming the images that evade both sides - great is his power."

\section{Appendix.B:}

Translation of parts of al-Shifa (chapter 5, article 5, part 6 of physics) (Avicenna \& Ibrahim Madkour, 1970):

"We say that human soul (mind) is potentially intelligent, and then becomes actually intelligent, and anything which goes from a potential to an actual needs a cause to actualize it. Thus, there is a cause which takes our soul from a potential state to an actual one in the ineligibles. The cause that grants the intelligible forms is not anything but the intellect which actually owns the incorporeal intelligible forms, and its relation to our souls is similar to the relation of sun to our eyes. Thus as sun is actually visible by itself and by sun's light we also see actually those things which are not actually visible by themselves, the same is true with the case of this intellect for our soul. Therefore, when the faculty of intellect is informed of imagination details (faculty of imagination), and the light of Active intellect, which is in ourselves, is shined on them, it become immaterial and free from the (properties of) matter and their attachments to it (matter), and is printed in our rational soul. It transfers from imagination to intellection neither by itself (by virtue of itself, non-in-itself) nor by that concepts that is impressed on the material attachments _...., inherently incorporeal_creates (new) like itself, but it means that the investigation of it, (l.e. by reflecting of these things in our imagination) prepares the soul to receive a form free from matter from Active 
intellect, so the (intellectual) laboring and thoughts are the movements which prepare the soul to accept the emanation (effusion), as well (because) the middle terms, via stronger emphasis, are disposed to accept the result; although the first (the susceptibility of mind to accept from active intellect) is through a way and the second (the susceptibility of middle terms to accept the results) is through another way, as you will soon know. Thus, when the rational soul gets a relation with the forms, through the Active intellect it receives something which in some sense is of the same genus and in another sense is different. Therefore, as the pictures received from the sensible things through a light is not the same as those things (, such as when the light shines to the coloreds, it effects on eye that is not the similar to that (light) in any aspects.)

Thus, the imaginations which are potential intelligibilia, become the actual intelligibilia not by itself, but what is captured from them is intelligible, such the effects of the sensible form (on the eye) via the light is not that form itself, but it is another thing, which is appropriate with that (sensible form), that is generated on the head-on recipient through the light. Such that is the intellective soul when investigate those imagination forms, and the light of active intellect connects to it (soul), through a type of connection, it disposes to which the light of active intellect creates on it those forms which is incorporeal from the (material) impurities."

\section{Appendix. C.}

Translation of parts of al-Shifa (chapter 4, article 4, part 6 of physics) (Avicenna \& Ibrahim Madkour, 1970c):

"We say that: it is a property of soul to produce, in the body (bodily element), an alteration (a qualitative change) which a constitution (temperament) is occurred (created) without any physical action or reaction. Thus, a heat is produced (on the body) not through a hot source or a cold from a cold source. But when the soul envisages an imagination, and it is strong in the mind, the bodily element instantly takes an appropriate form for that imagination.

This is because that the soul is formed from a substance (basis, principles) that resembles the form of material substances. Because the soul is closer (appropriate) to this substance (form) than others. When a matter takes a form that its capacity for acceptance is completed; and most aptitudes are created due to the alteration in quality as we mentioned earlier, and mostly it is altered by its around opposites, and when these principles covers a constituent form of natural species on the (bodily) element due to the (special) ratio between them, so it is not unlikely that, in addition, the qualities will covered on it without any need to the generation of the tangency and physical action and emotion which are issued from (by) opposites,

But the form which is in the human (soul) is the origin of what occurs in element, as the healthy form in the mind of physician is the origin of health (in the patient). Also the form of a bed in the mind of carpenter (leads to the production of a bed). Although form is from the basis that cannot lead to the result unless there are tools and means, due to its inability and weakness.

Look at the state of an ill person who imagines (health) and becomes healthy, and the healthy person who imagines (illness) and becomes ill, what often happens is that when a form appears in the mind (soul) and 
in its estimation, an element (of body) is affected by it, and health or illness appears, and this is more effective than when the physician does something by tools and mediations,

Thus, it is possible, e.g. that a person runs on a truck fallen in the road, but, if it be a case such as a bridge under which is a precipice, he does not walk on it except with caution, because he strongly imagines the form of falling in his mind, thus its nature follows it.

It is possible that a soul affects the body of another person, as his body is affected by other's evil eye or other's estimation, thus when the soul was strong, virtuous and similar to the principles, then the element, which is in the world, follows it and is affected by it, and it is found in the element what is imagined by it."

\section{Acknowledgements}

We are grateful to Dr. T. Jamali for her useful comments, and thank the many people who contributed to this work, especially Dr. M. Khatiri, A. Ayatollah Rafsanjani, M. Ansarifard and professor A.R Obodiat.

\section{References:}

Aminian, M. (2018). Principles of islamic philisophy Ghom: Boostan e K/ etab Ghom.

Avicenna, \& Danaseresht, A. (1985). Ravanshenasi e Shefa (Psycology of Shifa, persian translation of sixth part (art) of physics of al-Shifa) Tehran: Amir Kabir.

Avicenna, \& Madkour, I. (1969). al-Nafs (Psycological part of Healing), al-Shifa (the Healing): Dar o alKateb al-Arabi.

Avicenna, \& Madkour, I. (1970a). about the actions of representation faculty and thought faculty which are of the internal senses, al-Shifa (the Healing). Ghom: Maktabata Ayat o Allah al-ozma alMarashi al-Najafi.

Avicenna, \& Madkour, I. (1970). about the Active intellect which is in our soul and ... al-Shifa (the Healing) (pp. 208-209). Ghom: Maktabata Ayat o Allah al-ozma al-Marashi al-Najafi.

Avicenna, \& Madkour, I. (1970b). about the brain and its anatomy ... \& benefits of nerve and its anatomy from the brain, al-Shifa (the Healing). Ghom: Maktabata Ayat o Allah al-ozma al-Marashi alNajafi.

Avicenna, \& Madkour, I. (1970c). about the states of motive faculty and about the prophecy which related to it, al-Shifa (the Healing) (pp. 176-177). Ghom: Maktabata Ayat o Allah al-ozma alMarashi al-Najafi.

Avicenna, \& Madkour, I. (1970d). the first part of physics (fann e al-samae ai-tabiei), the first articl, chapter tow al-Shifa (the Healing). Ghom: Maktabata Ayat o Allah al-ozma al-Marashi al-Najafi.

Avicenna(Ibn-Sina). (980-1037a). on the Terrestrial and Celestial Souls, Chapter 2, 3 \& 4, Al-Isharat WaAl-Tanbihat (Remarks and Admonitions).

Avicenna(Ibn-Sina). (980-1037b). on the Terrestrial and Celestial Souls, Chapter 5, Al-Isharat Wa-AlTanbihat (Remarks and Admonitions).

Avicenna(Ibn-Sina). (980-1037c). on the Terrestrial and Celestial Souls, Chapter 10, Al-Isharat Wa-AlTanbihat (Remarks and Admonitions).

Avicenna(Ibn-Sina). (980-1037d). on the Terrestrial and Celestial Souls, Chapter 25\&26, Al-Isharat Wa-AlTanbihat (Remarks and Admonitions).

Avicenna(Ibn-Sina). (980-1037e). the Physics of Healing (Sama 'e Tabiei al-Shifa), Al-Shifa. 
Beck, F., \& Eccles, J. C. (1994). Quantum aspects of brain activity and the role of consciousness, How the Self Controls Its Brain (pp. 145-165): Springer.

Black, D. L. (2008). Avicenna on self-awareness and knowing that one knows, The Unity of Science in the Arabic Tradition (pp. 63-87): Springer.

Corbin, H. (2014). Avicenna and the Visionary Recital:(Mythos Series) (Vol. 188): Princeton University Press.

Doty, R. W. (1998). The five mysteries of the mind, and their consequences. Neuropsychologia, 36(10), 1069-1076.

Elitzur, A. C., \& Vaidman, L. (1993). Quantum mechanical interaction-free measurements. Foundations of Physics, 23(7), 987-997.

Ellis, G. (2016). How can physics underlie the mind?: top-down causation in the human context: Springer.

Fayyazi, G. R., \& Yusufi, M. T. (2014). A Textbook in Philosophical Psychology Tehran: SAMT.

Hameroff, S., \& Penrose, R. (2014). Consciousness in the universe: A review of the 'Orch OR'theory. Physics of life reviews, 11(1), 39-78.

Inati, S. C. (2014). Ibn Sina's Remarks and Admonitions: Physics and Metaphysics: An Analysis and Annotated Translation: Columbia University Press.

Kaukua, J. (2015). Self-Awareness in Islamic Philosophy: Cambridge University Press.

Lagerlund, H. (2007). Forming the mind: Essays on the internal senses and the mind/body problem from Avicenna to the medical enlightenment (Vol. 5): Springer Science \& Business Media.

Latinus, A., Van Riet, S., \& Verbeke, G. (1973). Liber de Anima seu Sextus de Naturalibus I-II-III.

Libet, B. (1979). Can a theory based on some cell properties define the timing of mental activities? Behavioral and Brain Sciences, 2(2), 270-271.

Libet, B. (2009a). Mind time: The temporal factor in consciousness 27 \& 41. Harvard University Press.

Libet, B. (2009b). Mind time: The temporal factor in consciousness 184 . Harvard University Press.

Libet, B. (2009c). Mind time: The temporal factor in consciousness: Harvard University Press.

Malekshahi, H. (1990a). Avicenna Isharat va Tanbihat (H. Malekshahi, Trans. Vol. 1)564.154. Tehran: Soroush.

Malekshahi, H. (1990b). Avicenna Isharat va Tanbihat (H. Malekshahi, Trans. Vol. 1)46. Tehran: Soroush.

Marmura, M. (1986). Avicenna's "flying man" in context. The Monist, 69(3), 383-395.

Moallemi, H. (2016). Self and Soul in Islamic Philosophy, Verses and Traditions: Publishing Organization of Institute for Islamic Culture and Thought.

Motahhari, M. (2010). Philosophical articles (Maghalate falsafi) 39-40.Ghom: Sadra.

Penrose, R. (1994). Shadows of the Mind (Vol. 4): Oxford University Press Oxford.

Rahman, F. (1959). Avicenna's De Anima (Arabic Text): Being the Psychological Part of Kitāb Al-Shifā': Oxford University Press.

Razi, F. a.-d. M. i. U. (1990). Kitab Al-Mabahith Al-Mashriqiyah Fi IIm Al-Ilahiyat Wa-Al-Tabi lyat (Vol. 2)350-351. beirut.

Sperry, R. W. (1976). Changing concepts of consciousness and free will. Perspectives in Biology and Medicine, 20(1), 9-19.

Stapp, H. P. (2004). Mind, matter, and quantum mechanics, Mind, matter and quantum mechanics (pp. 81-118): Springer.

Toivanen, J. (2015). Fate of the Flying Man: Medieval Reception of Avicenna's Thought Experiment.

Vaidman, L. (2001). Are interaction-free measurements interaction free? Optics and Spectroscopy, 91(3), 352-357. 